\title{
Analisis Pola Persebaran Lokasi Perdagangan dan Jasa di Kota Tebing Tinggi
}

\author{
Indra Rachmat Setiawan, LuthfiMuta'ali dan Sudrajat
}

Masuk: 18042019 / Diterima: 1405 2019 / Dipublikasi: 30062019

(C) 2019 Fakultas Hukum dan IImu Sosial UNDIKSHA dan IGI

\begin{abstract}
This research aims to identify the utilization type of space which is located in secondary arterial road of Tebing Tinggi Municipality; to analyze the distribution pattern of trade and service bussiness' location in secondary arterial road of Tebing Tinggi Municipality. The type of this research is description with quantitative approach. The analytical technique uses descriptive analysis and nearest neighbors analysis with software ArcGIS 10.2. The result of this research shows in secondary arterial road is in good condition and has 2 types of hardening material which are concrete and asphalt. The pederstrian path is only part of the secondary arterial road and The space utilization for dominantly settlement, trade and service bussiness. The distribution pattern of trade and service bussiness shows there pertained to be clumped and there are 2 central clumps.
\end{abstract}

Key words: Space Utilization; Distribution Pattern; Trade and Services

Abstrak Penelitian ini bertujuan untuk Mengidentifikasi jenis pemanfaatan ruang yang berada di jalan arteri sekunder Kota Tebing Tinggi, Menganalisis pola persebaran lokasi perdagangan dan jasa di jalan arteri sekunder Kota Tebing Tinggi. Jenis penelitian ini deskriptif dengan kuantitatif.Teknik analisis deskriptif dan analisis tetangga terdekat dengan bantuan software ArcGIS 10.2. Hasil penelitian menunjukan kondisi jalan arteri sekunder yang tergolong baik dengan material pengerasan aspal dan beton, jalur pederstrian hanya terdapat disebagian dari jalan arteri sekunder dan pemanfaatan ruang didominasi permukiman dan perdagangan dan jasa. Pola persebaran lokasi perdagangan dan jasa tergolong mengelompok dan terdapat 2 pusat pengelompokan.

Kata kunci : Pemanfaatan Ruang; Pola Persebaran; Perdagangan dan Jasa

\section{Pendahuluan}

Pembangunan adalah suatu proses yang dilakukan secara terus menerus dalam rangka memperbaiki indikator sosial maupun ekonomi pada suatu wilayah dari waktu ke waktu. berarti bahwa pembangunan senantiasa beranjak dari suatu keadaan atau kondisi kehidupan yang kurang baik menuju suatu kehidupan yang lebih baik dalam rangka mencapai tujuan nasional suatu bangsa didalam wilayah yang ditempati.

$$
\text { Kota Tebing Tinggi dalam }
$$

Rencana Tata ruang Wilayah Provinsi Sumatera Utara tahun 2013-2033, masuk kedalam sistem perkotaan dan tergolong sebagai Pusat Kegiatan Wilayah (PWK) sehingga diarahkan sebagai fungsi

Indra rachmat Setiawan, LuthfiMuta'ali dan Sudrajat Universitas Gadjah Mada, Yogyakarta

indrrachmat@yahoo.co.id pemerintahan kota dan fungsi perdagangan dan jasa. Perda No 4 tahun 2013 tentang Penataan Ruang Kota Tebing Tinggi memiliki tujuan sebagai Kota jasa dan perdagangan dalam konstelasi pengembangan wilayah Kawasan Strategis Nasional (KSN) Mebidangro dan Kawasan Pantai Timur Sumatera Utara yang aman, nyaman, produktif dan berkelanjutan.

Sektor perdagangan dan jasa merupaan salah satu faktor terpenting dan perlu di pertimbangkan karena sektor perdagangan dan jasa mempunyai peranan yang nyata dalam pembangunan ekonomi di suatu wilayah, manfaat yang di timbulkan langsung menanggulangi kesulitan ekonomi melalu peluang usaha dan penyediaan lapangan pekerjaan di wilayah tersebut. Terciptanya peluang usaha akan berdampak lanjut pada 
penambahan fasilitas yang mendukung kegiatan perdagangan dan jasa.

Secara alami banyak sistem jaringan yang tersedia tersebut maka semakin mudah aksesibilitas yang didapat, begitu pula sebaliknya semakin rendah tingkat aksesibilitas yang didapat maka semakin sulit daerah itu dijangkau dari daerah lainnya Bintarto (1982). Kota Tebing Tinggi di juluki sebagai Golden Triangle (segitiga emas) penghubung antara mebidangro (Medan, Binjai, Deliserdang dan Karo)dan Pantai Timur Sumatera Utara (Serdang Bedagai, Siantar, Batubara, Kisaran, Tanjung Balai) dikarenakan posisinya yang strategis. Perkembangan lahan terbangun cenderung mendekati lokasi dengan aksesibilitas tinggi terhadap infrastruktur/jaringan jalan maupun pusat kegiatan kota. Umumnya hal ini terjadi pada daerah pertumbuhan baru di sepanjang jalan utama kota dan regional.

Hal ini sesuai dengan model perjalanan fisik kota secara memanjang, dimana pola perkembangannya mengikuti pola jaringan jalan Northam dalam Yunus (1994). Babcock dalam Yunus (2000) mengemukakan hal yang sama dalam teori poros yang menjelaskan daerah di sepanjang jalur trasportasi memiliki mobilitas yang tinggi, sehingga perkembangan fisiknya akan lebih pesat dibandingkan daerah-daerah di antara jalur transportasi. Hasil penelitian Abdor dkk (2016) pembangunan jaringan jalan, menimbulkan maknet bagi masyarakat luar untuk berinfestasi atau bermukim. Setyawarman (2009) meneliti, valiabel aksesibilitas merupakan variabel penting dalam pemilihan lokasi retail dikarenakan dekatnya dengan lalu lintas umum dan memiliki akses langsung terhadap lalu intas harian. Groote dkk (1999) menganalisis hubungan antara total investasi infrastruktur dan pertumbuhan PDB di abad ke-19. Mereka menyimpulkan bahwa investasi inftrasturktur memiliki pengaruh positif terhadap pertumbungan. Berdasarkan data PDRB Kota Tebing Tinggi atas harga berlaku tahun 2005 sektor yang menjadi sektor basis adalah sektor jasa-jasa (jasa trasportasi dan pergunagan; jasa administrasi pemerintahan; jasa keuangan; jasa pendidikan dan jasa kesehatan) yang mencapai $33,49 \%$ atau hampir menyumbang sebagian besar pendapatan daerah di Kota Tebing Tinggi dan sektor kedua adalah Perdangan, Hotel dan Restoran yang mencapai $21,51 \%$.

Mengacu pada Perda RT/RW Kota Tebing Tinggi yang memiliki tujuan sebagai kota Perdagangan dan jasa serta lokasinya yang strategis dan dilihat dari PDRB Kota Tebing Tinggi yang bersumber dari sektor perdagangan dan jasa sehingga penulis untuk mencoba melihat bagaiman strategi pengembangan kawasan perdagangan dan jasa di Kota Tebing Tinggi kedepan

\section{Metode}

Penelitian ini megunakan pendekatan deduktif dengan metode analisis kuantitatif. Penelitian ini dimulai dari teori-teori yang sudah ada kemudian melihat kenyataan di lapangan. Sesuai dengan tujuan penelitain, maka terlebih dahulu dilakaukan pemantapan yang berkaitan dengan jenis kegiatan perdagangan dan jasa. Selanjutnya di tetapkan variabel-variabel penelitian yang kemudian dibuktikan dilapangan dengan observasi lapangan.

Lokasi penelitian berada di Kota Tebing Tinggi yakni pemanfaatan ruang di jalan arteri sekunder. Berdasarakan perda no 4 tahun 2013 tentang Rencana Tata Ruang Wilayah Kota Tebing Tinggi terdapat 14 nama jalan yang tergolong jalan arteri sekunder. Guna mempermudah dalam penelitian jalan ateri sekunder dibagi kedalam 6 jalur.

Peta jalur penelitian seperti terlihat pada Gambar 1. 


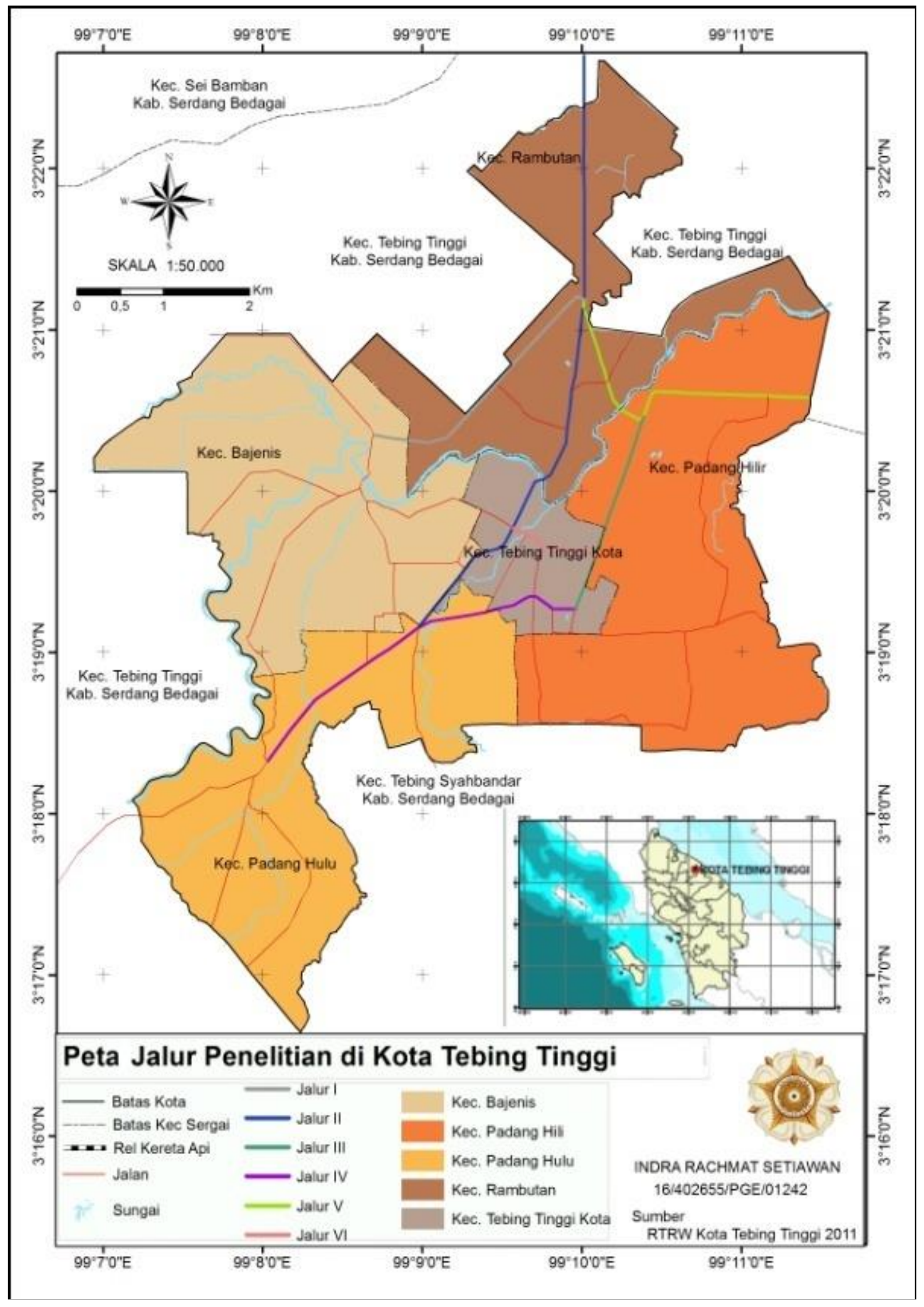

Gambar 1 Peta Jalur Penelitian 


\section{Hasil Dan Pembahasan}

\subsection{Jalur}

Pada Gambar 2 huruf A memiliki lebar 12 meter dan material pengerasan rigid beton serta terbagi menjadi 2 lajur yang dipisahkan oleh marka jalan atau pembatas jalan berupa tanaman-tanaman. Gambar 2 huruf E menujukan jalan dengan dimensi 5 meter dengan material pengerasan aspal. $\mathrm{Di}$ Jalur I, tidak ditemukan jalur pedestrian ataupun jalur pedestrian tidak memiliki elevasi dengan badan jalan yang dapat dilihat pada Gambar 2 huruf D dan Gambar 2 huruf F.
Jenis pemanfaatan yang mendominasi di jalur I dapat dilihat pada tabel 1. Permukiman dengan jumlah mencapai 161 unit atau sekitar 68,22\% (Gambar 2 huruf $\mathrm{G}$ ) dari jumlah total pengunaan lahan sebanyak 231 pengunaan lahan, angka ini didapat setelah melakkan observasi di lapangan. Rencana pola ruang yang ada pada RTRW Kota Tebing Tinggi, sebagian jalur I ditetapkan sebagai kawasan perkantoran dengan jumlah mencapai 10 unit dan kawasan industri yang mencapai 9 unit, salah satunya berupa pabrik karet (Gambar 2 huruf $\mathrm{H}$ ).

Tabel.1 Jenis Pemanfaatan Ruang Jalur I

\begin{tabular}{|l|r|r|}
\hline Jenis Pemanfaatan Ruang & Jumlah & Persentase \\
\hline Permukiman & 161 & 68,22 \\
\hline Bangunan & 15 & 6,36 \\
\hline Perdagangan Dan Jasa & 11 & 4,66 \\
\hline Ruang Terbuka & 15 & 6,36 \\
\hline Perkantoran & 10 & 4,23 \\
\hline Industri & 9 & 3,82 \\
\hline Fasilitas Sosial & 10 & 4,23 \\
\hline Tempat Makan Dan Minum & 5 & 2,12 \\
\hline Jumlah & 236 & 100 \\
\hline
\end{tabular}

Sumber: Data Primer, 2018

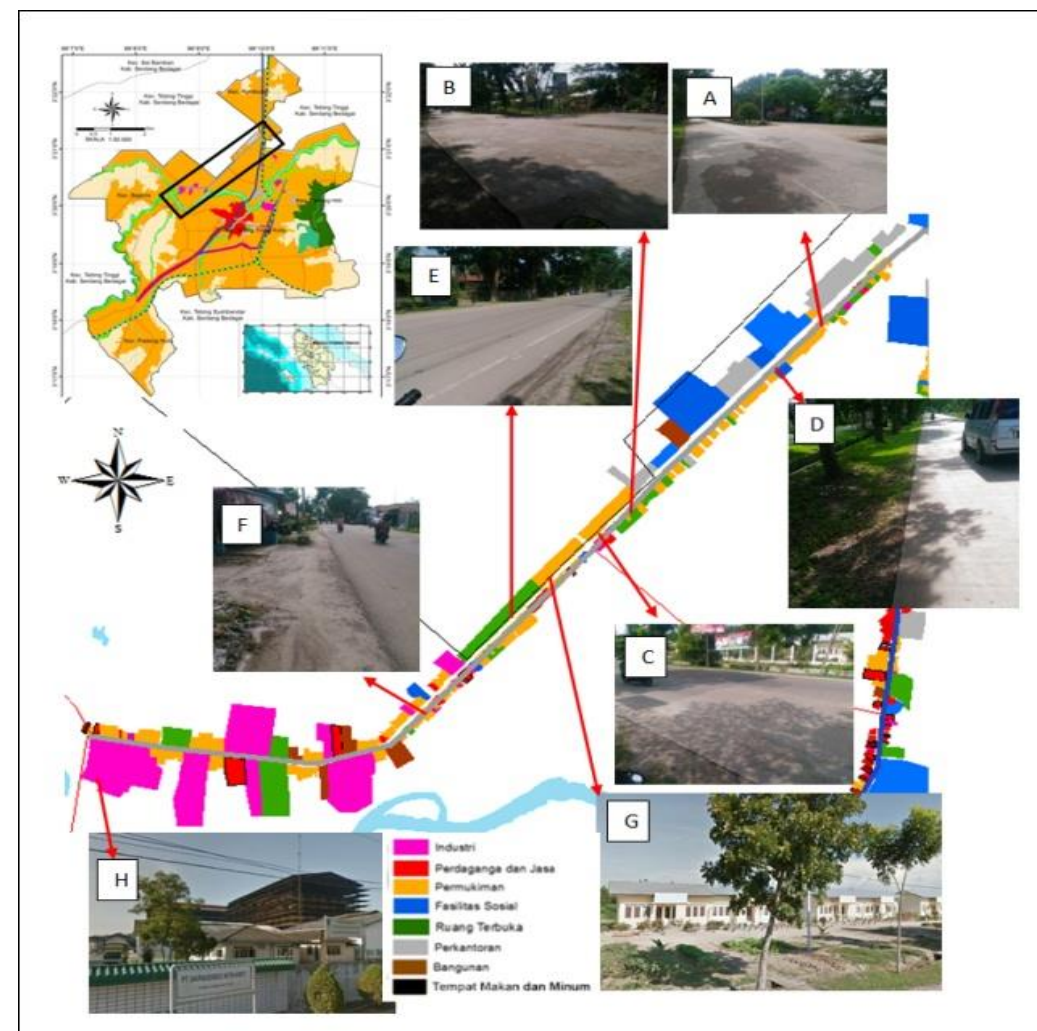

Gambar. 2 Jalur I (JI. Gunung lauser, Jl. H. Ir. Juanda) 


\subsection{Jalur II}

Jalur II memiliki dimensi yang berbada-beda akan tetapi material pengerasan yang sama yaitu aspal. Pada gambar 5.3 huruf I yang memiliki dimensi 24 meter. Pada gambar 5.3 huruf $\mathrm{J}$ dengan dimensi 12 meter, Gambar 5.3 huruf $\mathrm{K}$ dimensi 14 meter.

Jalur II memiliki jalur pedestrian dengan panjang 5.800 meter material keramik dan lebar kiri 1,5 meter lebar kanan 1,5 meter dan berdasarkan hasil observasi terdapat beberapa titik yang kondisinya kurang baik serta terdapat vegetasi peneduh yang berada di jalur pedestiran (Gambar 3 huruf L). Di beberapa tempat terdapat jalur pedestrian yang rusak yang memiliki panjang \pm 10 meter (Gambar 3 huruf M). Dibeberapa titik terdapat penutup gorong-gorong yang hilang (Gambar 3 huruf N). Secara keseluruhan kondisi pedestrian tergolong karegori baik (Gambar 3 huruf $O$ ).

Tabel 2, menunjukan jalur II di dominasi oleh kegiatan permukiman mencapai 372 unit atau 38,04\%. Pemanfaatan ruang berupa perdagangan dan jasa mencapai 253 unit sekitar 25,87 $\%$ (Gambar 3 huruf $P$ ), Bangunan seperti ruko sebanyak 204 (Gambar 3 huruf Q) dan total pengunaan lahan seluruhnya untuk lokasi II mencapai \pm 978 unit.

Tabel 2 Jenis Pemanfaatan Ruang Jalur II

\begin{tabular}{|l|r|r|}
\hline Jenis Pemanfaatan ruang & Jumlah & Persentase \\
\hline Permukiman & 372 & 38,04 \\
\hline Bangunan & 204 & 20,86 \\
\hline Perdagangan Dan Jasa & 253 & 25,87 \\
\hline Ruang Terbuka & 39 & 3,99 \\
\hline Perkantoran & 18 & 1,84 \\
\hline Industri & 4 & 0,41 \\
\hline Fasilitas Sosial & 34 & 3,47 \\
\hline Tempat Makan Dan Minum & 54 & 5,52 \\
\hline Jumlah & 978 & 100 \\
\hline
\end{tabular}

Sumber: Data Primer, 2018

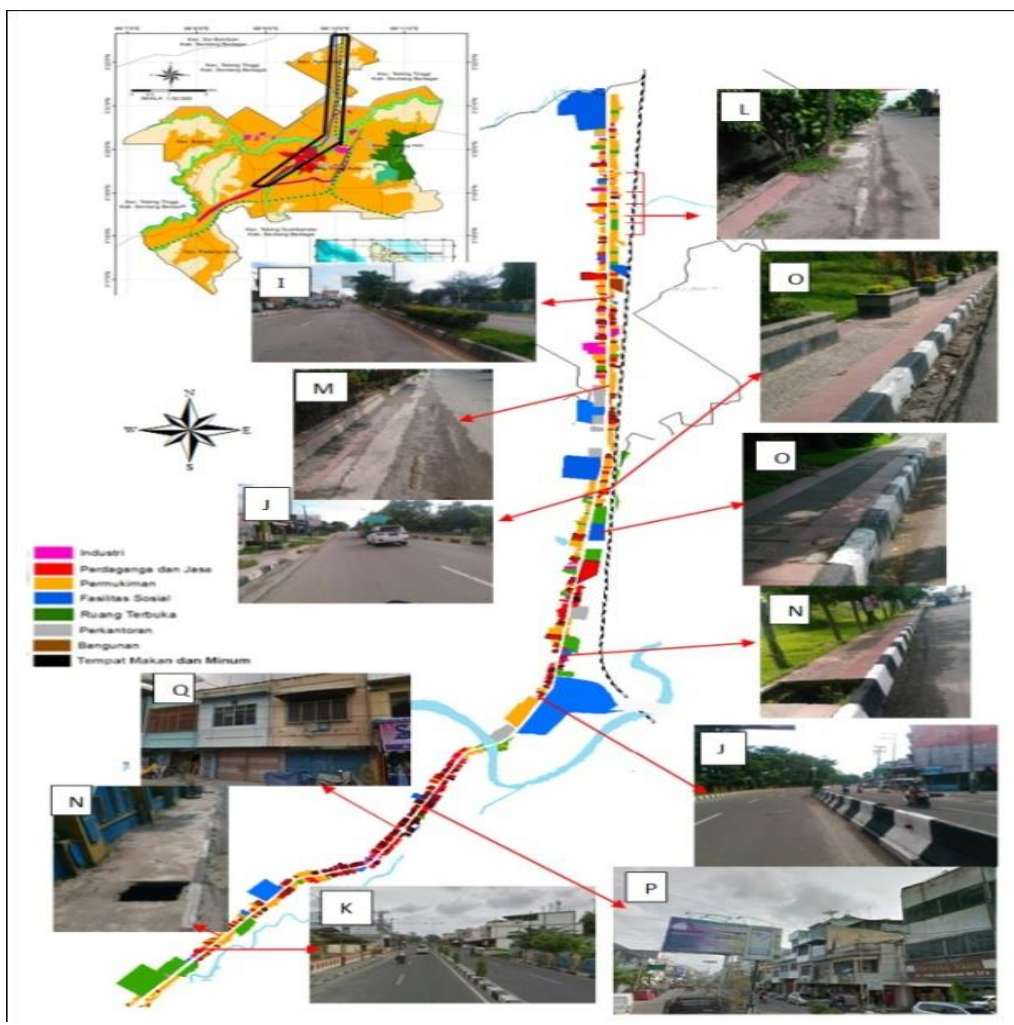

Gambar. 3 Jalur II (Jl. Kom Laut Yossudarso;Jl. Jend Sudirman; Jl. Jendral A. Yani) 


\subsection{Jalur III}

Jalur III terdiri dari dua jalan yakni Jl. Imam Bonjol $\pm 1,6 \mathrm{~km}$, Jl. Mayjen Sutoyo $\pm 1 \mathrm{~km}$, lokasi ini memiliki panjang $\pm 2,6$ $\mathrm{km}$ dengan dimensi 12 meter serta material aspal, dapat dilihat pada (Gambar 4 huruf R) dan (Gambar 4 huruf S). Jl Imam Bonjol dibagi menjadi 2 lajur kiri dan kanan, pembagian lajur kiri dan lajur kanan yang dipisahkan oleh marka jalan/pembatas serta terdapatnya lampu penerangan yang terpasang (Gambar 4 huruf $R$ ) sumber data dinas pekerjaan umum dan hasil obsrvasi.
Bentuk fisik pedestrian dijalur ini dengan material berupa keramik dengan lebar 1,15 meter (Gambar 4 huruf T). Di Jl. Mayjen Sutoyo tidak terpat jalur pedestrian (Gambar 4 huruf V).

Pemanfaatan ruang yang terdapat pada tabel 3 didominasi oleh permukiman sebanyak 108 unit sekitar $45 \%$ (Gambar 4 huruf W ), banunan ruko sebanyak 35 unit (Gambar 4 huruf X) serta perdagangan dan jasa sebanyak 52 unit sekitar 21,67\% (Gambar 4 huruf $Y$ ).

Tabel 3 Jenis Pemanfaatan Ruang Jalur III

\begin{tabular}{|l|r|r|}
\hline Jenis Pemanfaatan Ruang & Jumlah & Persentase \\
\hline Permukiman & 108 & 45,00 \\
\hline Bangunan & 35 & 14,58 \\
\hline Perdagangan Dan Jasa & 52 & 21,67 \\
\hline Ruang Terbuka & 14 & 5,83 \\
\hline Perkantoran & 12 & 5,00 \\
\hline Industri & 2 & 0,83 \\
\hline Fasilitas Sosial & 15 & 14,58 \\
\hline Tempat Makan Dan Minum & 25 & 6,25 \\
\hline Jumlah & 240 & 100 \\
\hline
\end{tabular}

Sumber: Data Primer, 2018

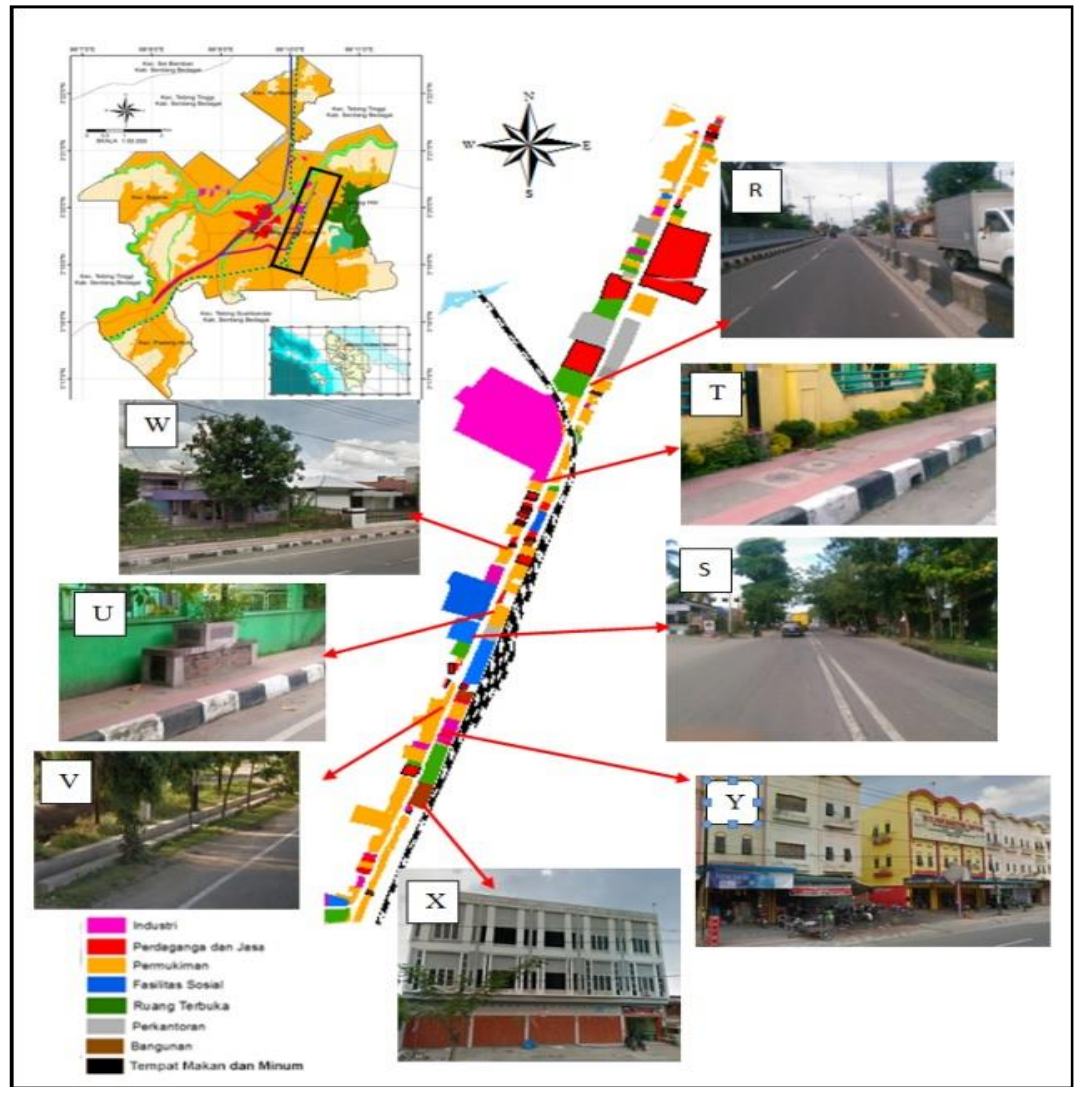

Gambar. 4 Jalur III (Jl. Imam Bonjol, JI. Mayjen Sutoyo) 


\subsection{Jalur IV}

Jalur IV JI.Diponegoro $\pm 0,515 \mathrm{~km}$, Jl. Sisimangaraja $\pm 1,37 \mathrm{~km}$, Sebagian Jl. Gatot Subroto $\pm 2,38 \mathrm{~km}$. Panjang jalur IV secara keseluruhan adalah $\pm 4,265 \mathrm{~km}$ dengan material aspal dan dapat dilihat pada Gambar 5 huruf $Z$, AA dan AB dengan dimensi yang berbeda. Gambar 5.5 huruf $\mathrm{Z}$, Jl Diponegoro memiliki dimensi 12 meter, jl. Sisimangaraja dengan dimensi 14 meter Gambar 5 Huruf AA dan sebagian jalan Gatot Subroto dengan dimensi 8 meter (Gambar 5 Huruf $A B$ ).

Pada jalur IV jalur pedestrian memiliki kondisi fisik yang berfariasi. di Jl.
Diponegoro, tidak terlihat jalur pedestrian (Gambar 5 huruf AC). Sebagian JI.Sisimangaraja terdapat jalur pedestrian, akan tetapi kondisi fisik yang rusak dan terdapat vegerasi dijalur pedestrian (Gambar 5 huruf AD) dan sebagian lagi tidak memiliki jalur pedestrian(Gambar 5 huruf $A E)$. Sedangkan di JI.Gatot subroto terdapat jalur pedestrian dengan kondisi fisik yang baik, dengan material pembentuknya keramik (Gambar.5 huruf AF) dan pavling blok (Gambar 5 huruf $A G)$, dibeberapa titik terdapat vegetasi yang tumbuh dijalur pedestrian (Gambar 5 huruf $A H)$.

Tabel 4 Jenis Pemanfaatan Ruang Jalur IV

\begin{tabular}{|l|r|r|}
\hline Jenis Pemanfaatan Ruang & Jumlah & Persentase \\
\hline Permukiman & 313 & 58,61 \\
\hline Bangunan & 81 & 15,17 \\
\hline Perdagangan Dan Jasa & 68 & 12,74 \\
\hline Ruang Terbuka & 34 & 6,36 \\
\hline Perkantoran & 13 & 2,43 \\
\hline Industri & 1 & 0,19 \\
\hline Fasilitas Sosial & 23 & 4,31 \\
\hline Tempat Makan Dan Minum & 1 & 0,19 \\
\hline Jumlah & 534 & 100 \\
\hline
\end{tabular}

Sumber: Data Primer, 2018

Dari Tabel 4, total pemanfaatan ruang pada jalur IV sebanyak 534 unit. Jalur IV didominasi oleh permukiman 313 unit sekitar 58,61 \% yang sebagian besar terdapat pada jalan Gatot Subroto
(Gambar 5 huruf $\mathrm{Al}$ ), Bangunan ruko 81 unit, perdagangan sebanyak 68 unit terpusat pada jalan sisingamangaraja (Gambar 5 huruf AJ).

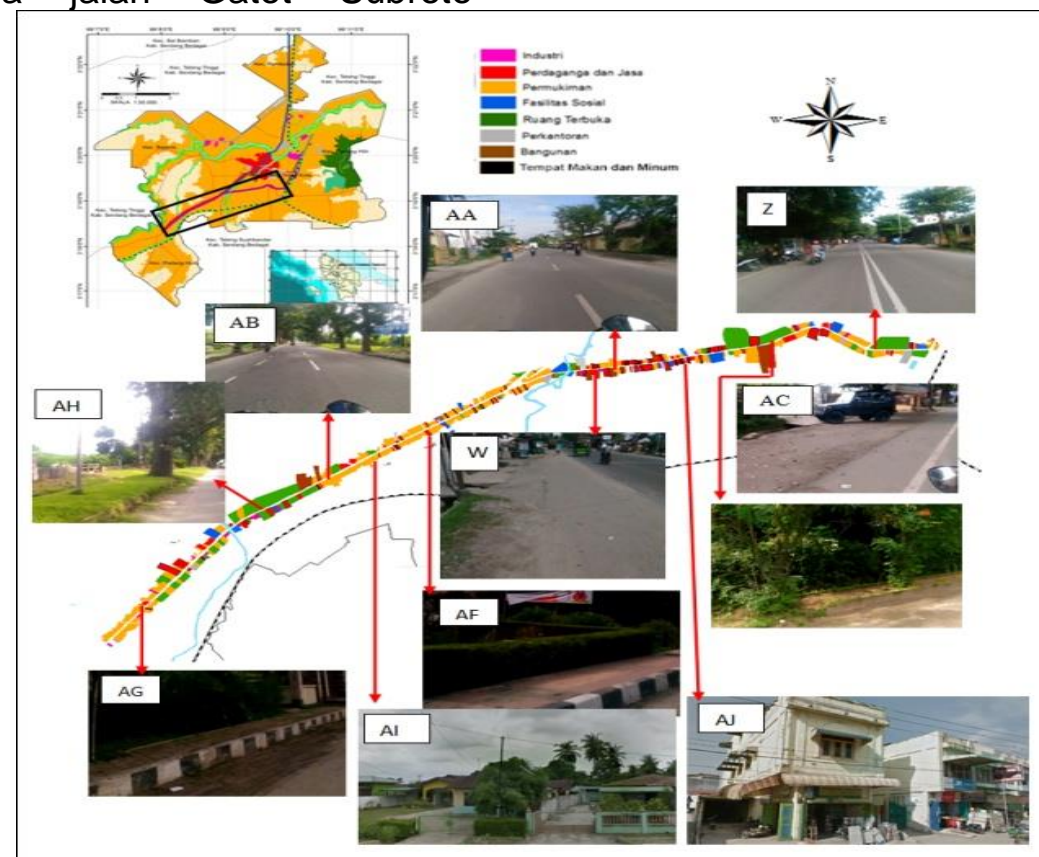

Gambar. 5 Jalur IV (Jl. Diponegoro, Jl. Sisimanga raja; Sebagian Jl. Gatot Subroto) 


\subsection{Jalur V}

Jalur $\mathrm{V}$ yang merupakan jalur lintas timur Sumatera Utara dari Kota Medan menuju wilayah timur Sumatera Utara. Jalur $\mathrm{V}$, terdapat dua jalan arteri sekunder yaitu Jl.Moh Yamin dengan panjang 1,5 $\mathrm{km}$ dan meterial pengerasan berupa aspal dengan lebar 8 meter (Gambar 6 huruf AK). Kedua Jl. Sukatno-Hatta dengan panjang 2,3 km dan lebar 8 meter dengan dua jenis material pengerasan berupa aspal dan beton (Gambar 6 huruf $A L$ ). Lajur dengan material aspal diperuntukan untuk satu lajur (Gambar 6 huruf AM). sedangkan jalur dengan material pengerasan beton diperuntukan untuk dua jalur kiri dan kanan dengan marka jalan sebagai pemisah lajur (Gambar 6 huruf AN). Jalur $\mathrm{V}$ tidak terdapatnya jalur pedestrian ataupun tidak ada elevasi antara badan jalan dengan jalur pedestrian (Gambar 6 Huruf AO dan AP).

Tabel 5 Jenis Pemanfaatan Ruang Jalur V

\begin{tabular}{|l|r|r|}
\hline Jenis Pemanfaatan Ruang & Jumlah & Persentase \\
\hline Permukiman & 113 & 41,39 \\
\hline Bangunan & 39 & 14,29 \\
\hline Perdagangan Dan Jasa & 31 & 11,35 \\
\hline Ruang Terbuka & 41 & 15,02 \\
\hline Perkantoran & 4 & 1,47 \\
\hline Industri & 8 & 2,93 \\
\hline Fasilitas Sosial & 20 & 7,32 \\
\hline Tempat Makan Dan Minum & 17 & 6,23 \\
\hline Jumlah & 273 & 100 \\
\hline
\end{tabular}

Sumber: Data Primer, 2018

Pemanfaatan ruang dominan adalah permukiman 113 unit sekitar 41,39\% (Gambar 6 Huruf AQ). ruang terbuka yang mencapai 15,02 \% atau sekitar 41 petak tanah yang belum dimanfaatkan (Gambar
6 Huruf AR). Pemanfaatan ruang perdagangan dan jasa menempati posisi ketiga dengan jumlah 31 unit atau sekitar $11,53 \%$.

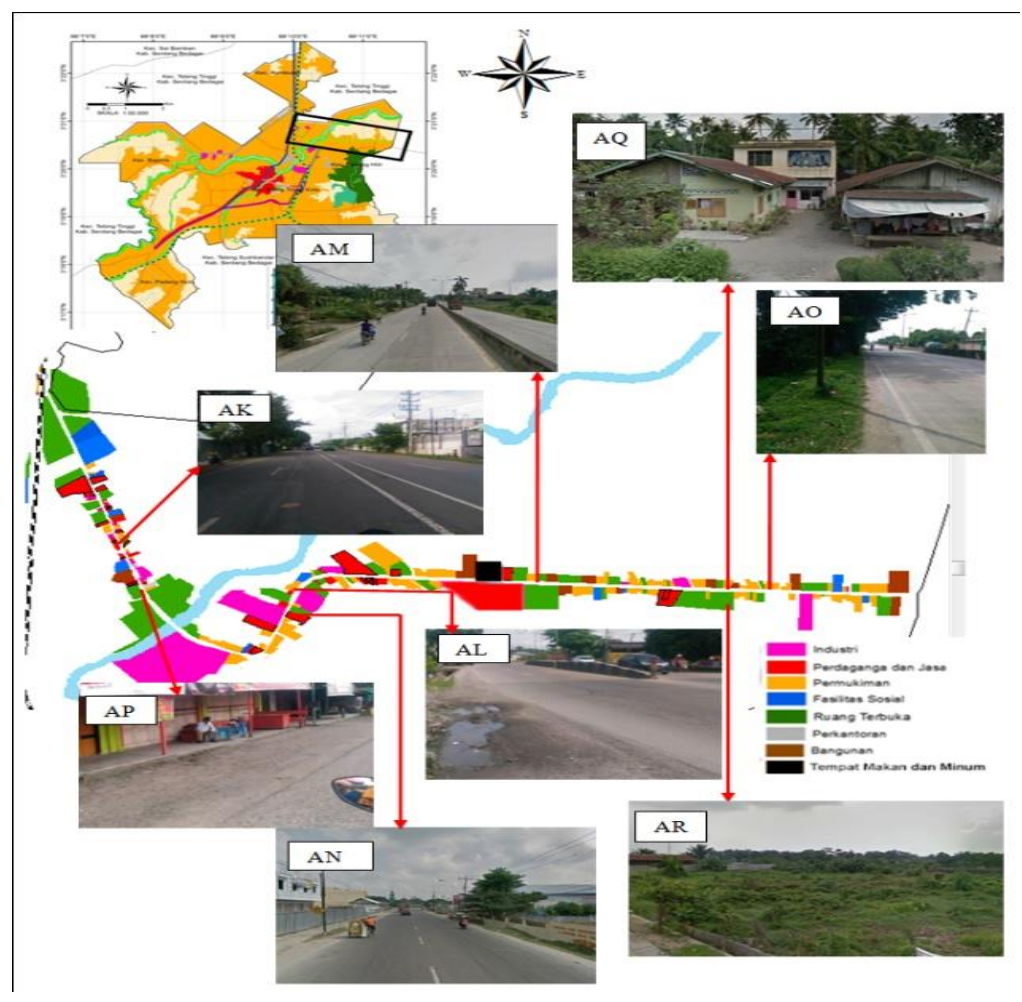

Gambar 6 Jalur V (JI.Moh Yamin Jl. Sukatno-Hatta) 


\subsection{Jalur VI}

Jalur VI merupakan lokasi terakhir yang diteliti dengan dua jalan arteri sekunder adalah Jl. Dokter Sutomo dengan panjang $\pm 0,7 \mathrm{~km}$ (Gambar 7 huruf AS) dan Jl. Suprapto dengan panjang \pm $0,5 \mathrm{~km}$, (Gambar 7 huruf AT) dimensi kedua jalan tersebut adalah 14 meter serta material pengerasan berupa aspal.
Kondisi fisik jalur pedestrian di Jl. Dokter Sutomo dengan lebar 1 meter untuk jalur kiri dan kanan serta material keramik (Gambar 7 huruf AU). Serta Jl. Suprapto dengan lebar 1,5 meter dan material keramik (Gambar 7 huruf AV. Secara keseluruhan kondsi jalur pedestrian pada jalur VI tergolong sangat baik.

Tabel 6. Jenis Pemanfaatan Ruang Jalur VI

\begin{tabular}{|l|r|r|}
\hline Jenis Pemanfaatan Ruang & Jumlah & Persentase \\
\hline Permukiman & 8 & 5,26 \\
\hline Bangunan & 23 & 15,13 \\
\hline Perdagangan Dan Jasa & 95 & 62,50 \\
\hline Ruang Terbuka & 1 & 0,67 \\
\hline Perkantoran & & 3,29 \\
\hline Industri & - & 0 \\
\hline Fasilitas Sosial & 10 & 6,58 \\
\hline Tempat Makan Dan Minum & 10 & 6,58 \\
\hline Jumlah & 152 & 100 \\
\hline
\end{tabular}

Sumber: Data Primer, 2018

Jalur VI ditetapkan sebagai kawasan perkantoran di J Dr.Sutomo, salah satu kantor pemerintahan yang terdapat dijalur VI adalah kantor walikota (Gambar 7 huruf AW), kantor keuangan RI (Gambar 7 huruf Y) dan kawasan perdagangan dan jasa di
JI. Suprapto (Gambar 7 huruf $A X$ ). Pemanfaatan ruang perdagangan dan jasa mendominasi pada jalur VI sekitar $62,50 \%$. Bangunan berupa ruko menpati posisi kedua dengan persentase sebesar $15,26 \%$.

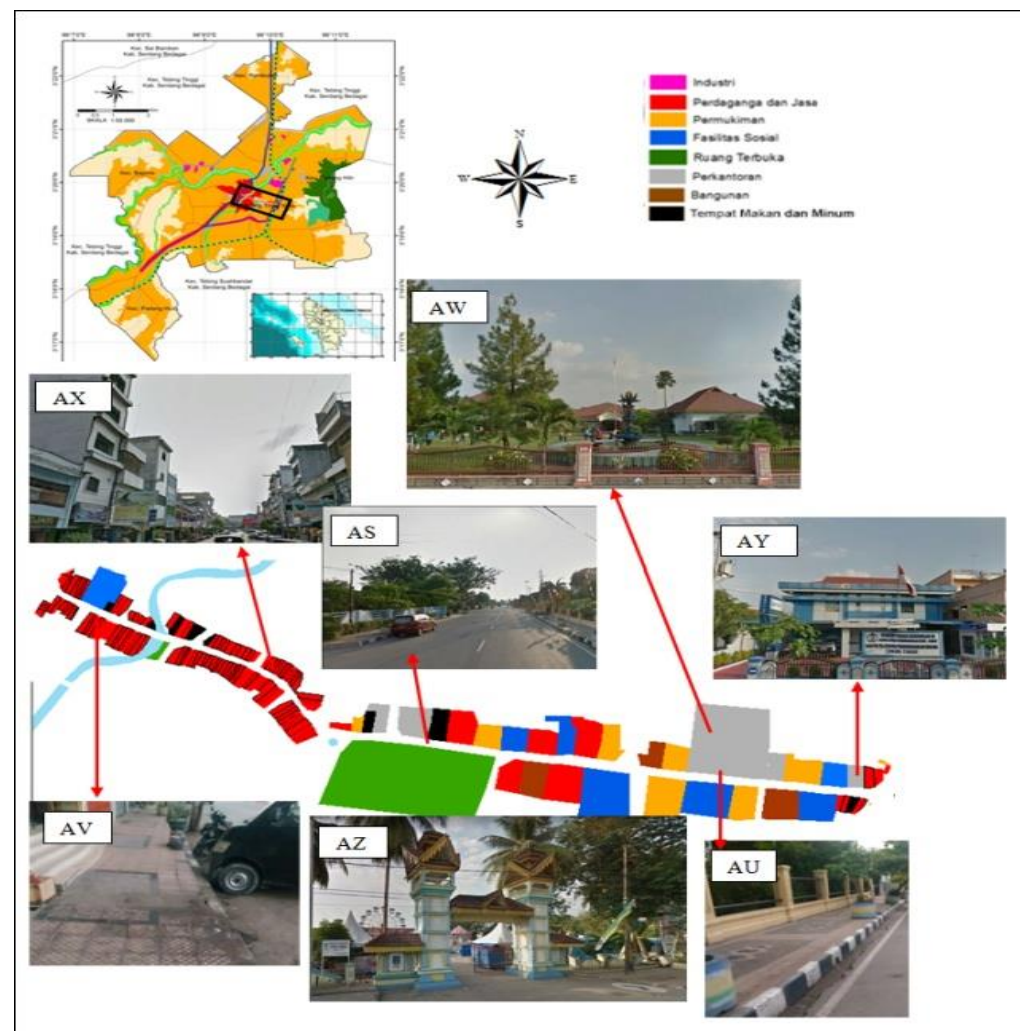

Gambar 7 Jalur VI (JI. Dokter Sutomo; Jl. Suprapto) 
Dalam penataan ruang terdapat fungsi yang harus ditetapkan dalam kawasan. Penentuan fungsi didasarkan pada kesesuaian dan kemampuan lahan dengan teknik generalisasi dan pendetailan. Dengan teknik generalisasi penetapan kawasan dilihat dari keterkaitan fungsi dan dominasi kegiatan. Dalam beberapa kasus penetapan fungsi kawasan tidak dilihat dari jumlah dan luas area tetapi dampak keterkaitan fungsional.

Pada Tabel 7 mencoba menghubungkan pemanfaatan ruang di sepanjang jalur dengan pola ruang Kota Tebing Tinggi. Pola ruang yang terdapat disepanjang jalur adalah kawasan industri, kawasan perdagangan dan jasa, kawasan permukiman kepadatan sedang, kawasan perkantoran dan ruang terbuka.

Tabel 7. Distribusi Pola Ruang di Jalan Arteri sekunder

\begin{tabular}{|c|c|c|c|c|c|c|c|c|c|c|c|}
\hline \multirow{3}{*}{ Jalur } & \multicolumn{10}{|c|}{ Rencana Pola Ruang Kota Tebing Tinggi tahun 2013-2033 } & \multirow{3}{*}{$\begin{array}{c}\text { Panjang } \\
\text { Jalur } \\
\text { (m) }\end{array}$} \\
\hline & \multicolumn{2}{|c|}{$\begin{array}{l}\text { Kawasan } \\
\text { Industri }\end{array}$} & \multicolumn{2}{|c|}{$\begin{array}{c}\text { Kawasan } \\
\text { Perdagangan } \\
\text { dan jasa }\end{array}$} & \multicolumn{2}{|c|}{$\begin{array}{l}\text { Kawasan } \\
\text { Permukiman } \\
\text { Kepadatan } \\
\text { Sedang }\end{array}$} & \multicolumn{2}{|c|}{$\begin{array}{c}\text { Kawasan } \\
\text { Perkantoran }\end{array}$} & \multicolumn{2}{|c|}{ Ruang Terbuka } & \\
\hline & $\begin{array}{l}\text { Panjang } \\
\text { (Meter) }\end{array}$ & $\%$ & $\begin{array}{l}\text { Panjang } \\
\text { (Meter) }\end{array}$ & $\%$ & $\begin{array}{l}\text { Panjang } \\
\text { (Meter) }\end{array}$ & $\%$ & $\begin{array}{l}\text { Panjang } \\
\text { (Meter) }\end{array}$ & $\%$ & $\begin{array}{l}\text { Panjang } \\
\text { (Meter) }\end{array}$ & $\%$ & \\
\hline$\underset{\text { Jalur }}{\text { Jal }}$ & 470,90 & 14,27 & & & 2415,40 & 73,19 & 413,40 & 12,53 & & & 3.300 \\
\hline $\begin{array}{c}\text { Jalur } \\
\text { II }\end{array}$ & 147,72 & 2,13 & 2208,26 & 31,77 & 4417,47 & 63,56 & & & 176,51 & 2,54 & 6.950 \\
\hline $\begin{array}{c}\text { Jalur } \\
\text { III }\end{array}$ & 106,52 & 4,10 & 1339,88 & 51,53 & 976,50 & 37,56 & & & 116,70 & 4,49 & 2.600 \\
\hline $\begin{array}{c}\text { Jalur } \\
\text { IV }\end{array}$ & & & 4264,26 & 99,98 & & & & & & & 4.265 \\
\hline $\begin{array}{c}\text { Jalur } \\
\mathrm{V}\end{array}$ & & & & & 3617,98 & 95,21 & & & 177,89 & 4,68 & 3.800 \\
\hline $\begin{array}{c}\text { Jalur } \\
\text { VI }\end{array}$ & & & 716,33 & 59,69 & & & 352,30 & 29,36 & 130,00 & 10,83 & 1.200 \\
\hline
\end{tabular}

Sumber: Data Primer, 2019

Tabel 7, memperlihatkan jalur I,II dan V ditetapkan sebagai kawasan permukiman kepadatan sedang. Jalur IV dan VI ditetapkan sebagai kawasan perdagangan dan jasa. Dalam peta pola ruang Kota Tebing Tinggi, jalur IV direncanakan sebagai kawasan perdagangan dan jasa. Penetapan ini didasarkan karena dampak yang ditimbulkan akibat keterkaitan funsional. Terkaitan tersebut berupak wilayah belakang jalur IV ditetapkan sebagai kawasan permukiman sedang dengang jumlah bangunan 40-100 rumah/hektar. Jumlah angktuan umum yang melewati jalur tersebut cukup banyak mencapai 53 unit dan terdapatnya jalur pedestrian dengan kondisi keseluruhan sangat baik .

\subsection{Pola Persebaran lokasi perdagangan dan jasa \\ Dari hasil analisis tetangga} terderkat dapat diketahui pola persebaran untuk setiap jenis usaha perdagangan dan jasa yang didasarkan pada patokan baku yaitu skala $T$, dimana 0-0,7 pola mengelompok, 0,7-1,4 pola acak dan 1,42,15 pola seragam. Dengan mengunakan fiture average nearest neighbor didalam software argis 10,2 maka analisis tetangga terdekat dapat dilakukan lebih mudah. 
Tabel 8. Hasil Analisis tetangga terdekat terhadap 10 jenis usaha

\begin{tabular}{|c|l|r|r|r|r|r|r|}
\hline No & \multicolumn{1}{|c|}{ Jenis Usaha } & $\begin{array}{c}\text { T (Nearest } \\
\text { Neighbor } \\
\text { Ratio) }\end{array}$ & $\begin{array}{c}\text { Z-Score } \\
\text { (Standard } \\
\text { Deviastion) }\end{array}$ & $\begin{array}{c}\text { P-Value } \\
\text { (Probability) }\end{array}$ & $\begin{array}{c}\text { Convidence } \\
\text { Level }\end{array}$ & $\begin{array}{c}\text { Jarak Rata- } \\
\text { Rata Titik } \\
\text { (meter) }\end{array}$ & Keterangan \\
\hline 1 & $\begin{array}{l}\text { Perdagangan } \\
\text { Besar; }\end{array}$ & 0,664561 & $-1,925155$ & 0,054210 & $99 \%$ & 686,7130 & Mengelompok \\
\hline 2 & $\begin{array}{l}\text { Perdagangan, } \\
\text { reparasi dan } \\
\text { perawatan mobil } \\
\text { dan sepeda motor; }\end{array}$ & 0,267087 & $-10,678186$ & 0,000000 & $99 \%$ & 108,7176 & Mengelompok \\
\hline 3 & $\begin{array}{l}\text { Perdagangan } \\
\text { eceran }\end{array}$ & 0,149259 & $-28,423541$ & 0,000000 & $99 \%$ & 26,4943 & Mengelompok \\
\hline 4 & Jasa pariwisata; & 2,042323 & 2,819994 & 0,004802 & $99 \%$ & 4476,835 & Seragam \\
\hline 5 & $\begin{array}{l}\text { Jasa Perawatan } \\
\text { Pribadi; }\end{array}$ & 0,647382 & $-2,940437$ & 0,003277 & $99 \%$ & 460,4109 & Mengelompok \\
\hline 6 & $\begin{array}{l}\text { Jasa Prawatan } \\
\text { Medis dan } \\
\text { kesehatan; }\end{array}$ & 0,331217 & $-3,838286$ & 0,000124 & $99 \%$ & 342,2576 & Mengelompok \\
\hline 7 & $\begin{array}{l}\text { Jasa Pendidikan } \\
\text { Privat dan Kursus; }\end{array}$ & 0,168480 & $-4,208743$ & 0,000026 & $99 \%$ & 197,4068 & Mengelompok \\
\hline 8 & $\begin{array}{l}\text { Jasa Bisnis dan } \\
\text { Profesi lainnya; }\end{array}$ & 0,371840 & $-8,061345$ & 0,000000 & $99 \%$ & 171,8349 & Mengelompok \\
\hline 9 & $\begin{array}{l}\text { Jasa Asuransi, } \\
\text { Bank dan Finance; }\end{array}$ & 0,205614 & $-8,183926$ & 0,000000 & $99 \%$ & 118,3626 & Mengelompok \\
\hline 10 & Jasa Trasportasi & 0,424004 & $-3,116703$ & 0,001829 & $99 \%$ & 465,748 & Mengelompok \\
\hline
\end{tabular}

Hasil perhitungan pada Tabel 8 dapat dilihat, jasa pariwisata dikategorikan seragam dilihat dari nilai $\mathrm{T}=2,042323$ yang berada diantara 1,4-2,15. Kesembilan usaha dikateorikan mengelompok dikarenakan nilai T berada diantara 0-0,7. Jika dilihat lebih detail, perolehan nilai $\mathrm{T}$ untuk jenis perdagangan besar dan jasa perawatan pribadi mendekati 0,7 sehingga distribusi pola distribusinya mendekati acak. Pengelompokan pusat perdagangan dan jasa yang diidentifikasi dengan memetakan seluruh sebaran sebaran usaha perdagangan dan jasa yang telah dilakukan sebelumnya dan analisis mengunakan analisis tetangga terdekat.

Diperoleh nilai $\mathrm{T}$ sebesar 0,160254 . Berdasarkan nilai tersebut pola persebaran lokasi perdagangan dan jasa termasuk dalam kategori mengelompok. Jarak rata-rata antar titik (perdagangan dan jasa) terdekatnya adalah 22,6751 meter (Gambar 8).

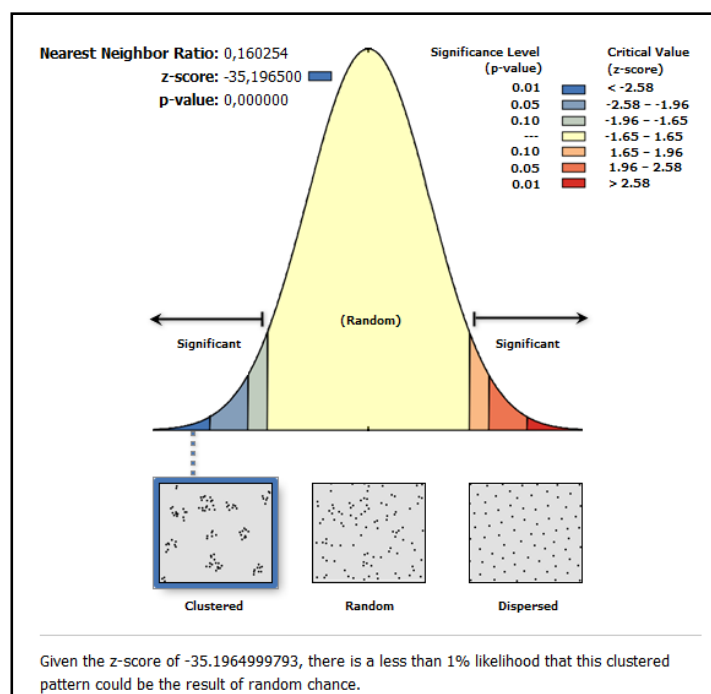

Average Nearest Neighbor Summary

Observed Mean Distance: 22,6751 Meters

Expected Mean Distance: 141,4950 Meters

Nearest Neighbor Ratio: 0,160254

z-score: $-35,196500$

p-value: 0,000000

Dataset Information

Input Feature Class: Gabungan_Pedagang_Jasa_Project_UTM

Distance Method: EUCLDEAN

Study Area: 38440000,000000

Selection Set: False

Gambar 8. Hasil Analisis Average Nearest Neighbor Lokasi Perdagangan dan Jasa di Jalan Arteri Sekunder Kota Tebing Tinggi 
Terdapat 2 titik fokus pusat pengelompokan perdagangan dan jasa di jalan arteri sekunder yang dapat dilihat pada gambar 9. Terdapat 359 unit usaha atau sekitar $73,41 \%$ perdagangan dan jasa terdapat pada 2 pusat pengelompokan tersebut.
Dipusat pengelompokan I terdapat 292 kegiatan usaha perdagangan dan jasa sekitar 59,7\% terdapat pada pusat pengelompokan I dan dipusat pengelompokan II terdapat 67 unit usaha atau sekitar $13 \%$ dari total seluruh perdagangan dan jasa. Perinciannya dapat dilihat pada Tabel 9.

Tabel 9 Jumlah Usaha dalam Pusat Pengelompokan

\begin{tabular}{|r|l|r|r|r|}
\hline \multirow{2}{*}{ No Jenis Usaha } & \multicolumn{1}{|c|}{$\begin{array}{c}\text { Jumlah Usaha dalam Pusat } \\
\text { Pengelompokan (Unit) }\end{array}$} & \multirow{2}{*}{ Jumlah } \\
\cline { 3 - 4 } & & \multicolumn{1}{|c|}{ II } \\
\hline 1 & Perdagangan Besar; & - & 1 & 1 \\
\hline 2 & $\begin{array}{l}\text { Perdagangan, reparasi dan perawatan mobil } \\
\text { dan sepeda motor; }\end{array}$ & 27 & 13 & 40 \\
\hline 3 & Perdagangan eceran & 215 & 31 & 246 \\
\hline 4 & Jasa pariwisata; & - & 1 & 1 \\
\hline 5 & Jasa Perawatan Pribadi; & 7 & 2 & 9 \\
\hline 6 & Jasa Prawatan Medis dan kesehatan; & 4 & 2 & 6 \\
\hline 7 & Jasa Pendidikan Privat dan Kursus; & - & 5 & 5 \\
\hline 8 & Jasa Bisnis dan Profesi lainnya; & 23 & 5 & 28 \\
\hline 9 & Jasa Asuransi, Bank dan Finance; & 16 & 7 & 23 \\
\hline 10 & Jasa Trasportasi & - & 1 & 1 \\
\hline & Jumlah & 292 & 68 & 360 \\
\hline
\end{tabular}

Sumber: Data Primer, 2019

\section{Kesimpulan}

Berdasarkan hasil pengumpulan dan analisis data dalam penelitian ini dapat dirumuskan beberapa kesimpulan. Pertama, Jalur II dan VI memiliki pedestrian dengan kondisi baik, Jalur III dan IV sebagian memiliki jalur pedestrian dengan kondisi baik dan sebagian lagi tidak terdapat beda tinggi antara jalur pedestrian dengan jalur jalan. Jalur I dan VI tidak memiliki pedestrian. Kondisi jalan yang terdapat di 6 jalur tergolong baik dan memiliki 2 jenis material pengerasan berupa beton dan aspal. Pemanfaatan ruang dominan adalah permukiman kepadatan sedang dan perdagangan dan jasa. Kedua, terdapat 9 jenis usaha kategori mengelompok dan 1 jenis usaha kategori seragam. Serta secara keseluruhan terdapat dua puast pengelompokan.

\section{Daftar Pustaka}

Abror S. M., Purwoko, Agus., dan Pratomo, W.A., (2016). Analisis Pengaruh Jaringan Jalan Terhadap
Perubahan Guna Lahan Di Kawasan Aek Kanopan. Jurnal Ekonomi. Vol.19, No. 2, hal. 8289.

Bintarto. (1975). Pengantar Geografi Pembangunan. PT. PB. Kedaulatan Rakyat. Yogyakarta.

BPS.(2017). Klasifikasi Baku Lapangan Usaha Indonesia. Republik Indonesia: BPS.

BPS. (2017). Produk Domestik Regional Bruto. Tebing Tinggi: BPS.

Groote, P., Jacobs, J., Sturm, J.E., (1999). Infrastructure and economic development in the Netherlands, 1853-1913. European Review of Economic History 2, 233-251.

Setyawarman, adityo.(2009), Pola sebaran dan faktor - faktor Yang mempengaruhi pemilihan Lokasi retail modern (studi kasus kota Surakarta). Semarang. Tesis Universitas Diponegoro.

Yunus, H. S. (2000). Struktur Tata Ruang Kota. Yogyakarta: Penerbit Pustaka Pelajar. 


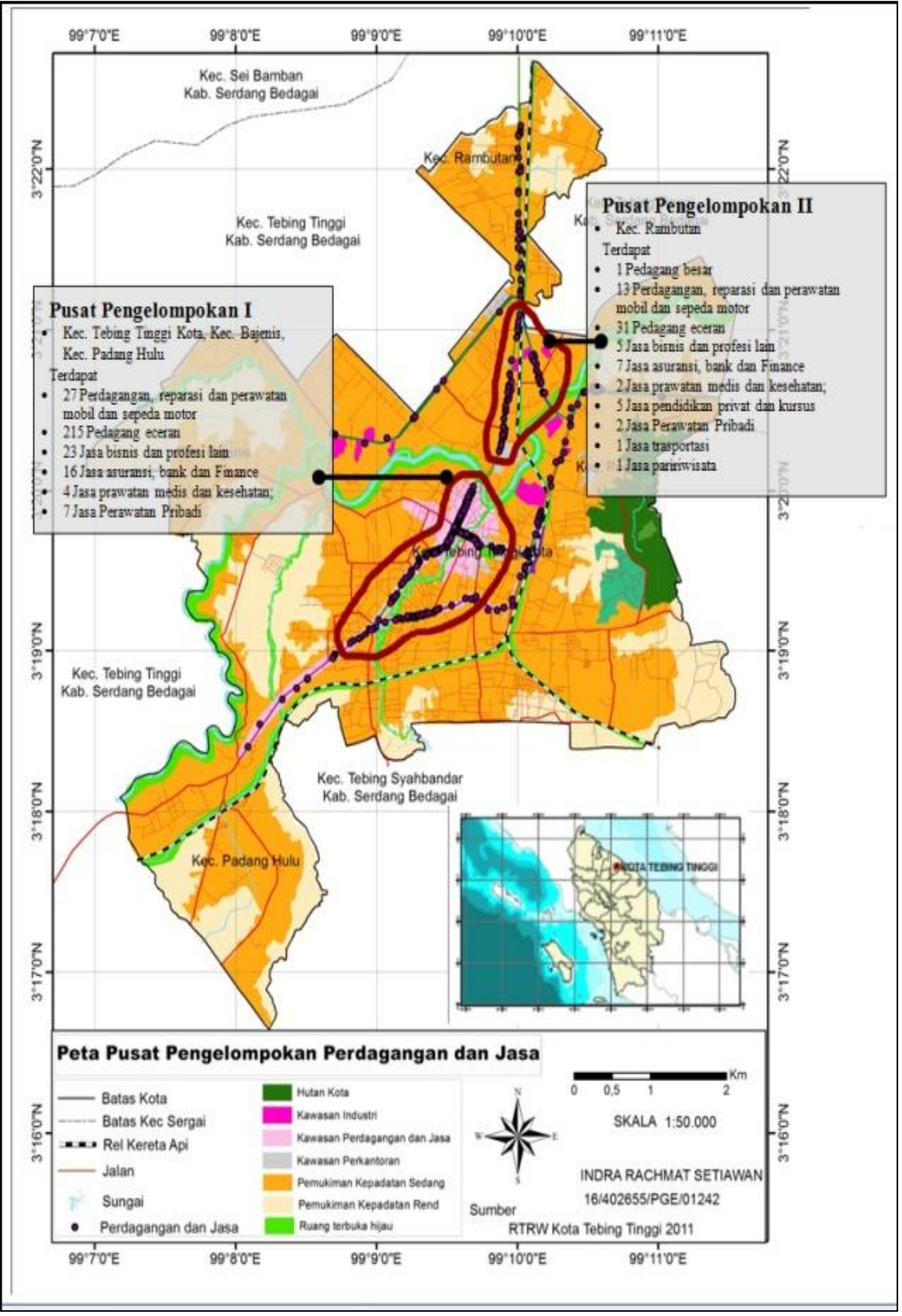

Gambar 9 Pusat pengelompokan lokasi perdagangan dan jasa di jalan arteri sekunder Kota Tebing Tinggi 